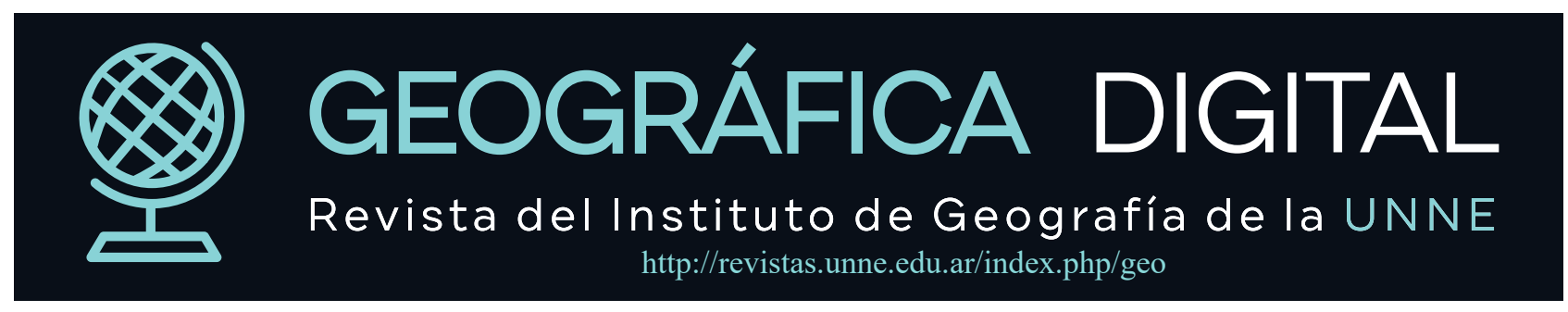

Revista Geográfica Digital, 2020, Vol. 17, №33, 61-79 pp., DOI: http://dx.doi.org/10.30972/geo.17334426

\title{
Narcotráfico y narcomenudeo como expresión de delito urbano en la ciudad de Clorinda
}

\section{Narcotraphic and narcomenudeo as expression of urban crime in the Clorinda city}

\section{Conte, Ricardo $0 .^{1}$ \\ Morel, Rodrigo J. ${ }^{2}$}

Fleitas, Marcos A. ${ }^{3}$

1Prof. Titular Ordinario. Carrera de Geografía. Facultad de Humanidades. Universidad Nacional de Formosa. ricardoomarconte@gmail.com ${ }^{2}$ Licenciando en Geografía. Carrera de Geografía. Facultad de Humanidades. Universidad Nacional de Formosa- GEOFOR. rodrigomorel892@gmail.com ${ }^{3}$ Licenciando en Geografía. Carrera de Geografía. Facultad de Humanidades. Universidad Nacional de Formosa- GEOFOR. fleitasmarcosa@gmail.com

Palabras claves:

\section{R E S U M E N}

Narcomenudeo Distribución espacial Puntos calientes ciudad de Clorinda

El tráfico de narcóticos es uno de los delitos más significativos en la ciudad de Clorinda, siendo el narcomenudeo uno de los eslabones de la cadena del narcotráfico. Este ha crecido en los últimos años en forma permanente y es llevado a cabo en su mayoría por jóvenes adictos que recurren a la venta al detalle de narcóticos para financiar sus propias adicciones.

Estos jóvenes adictos-dealers en muchos casos ni trabajan ni estudian, llegando frecuentemente a cometer otros tipos de hechos delictivos que aumentan la inseguridad urbana.

Este artículo referencia parte de un trabajo de investigación de cátedra llevado a cabo dentro del marco de la Geografía del Delito en el espacio geográfico y jurisdiccional de la ciudad de Clorinda, mediante el cual hemos podido determinar los barrios con mayor ocurrencia del delito de tráfico y comercialización de drogas ilícitas y las denominadas "zonas calientes" de concentración de hechos delictivos referidos a este flagelo que hace mella especialmente en la juventud y en los sectores más vulnerables de la sociedad.

\section{A B S T R A C T}

Narcotics trafficking is one of the most significant crimes in the city of Clorinda, with drug trafficking being one of the links in the drug trafficking chain. This has grown in recent years permanently and is mostly carried out by young addicts who resort to the retail sale of narcotics to finance their own addictions.

Clorinda city

Spatial distribution

Hot spots

Recibido: 26/02/2020

Aceptado: 20/06/2020
These young addicts-dealers in many cases neither work nor study, often committing other types of criminal acts that increase urban insecurity.

This reference article is based on a research project of the chair carried out within the framework of the Geography of Crime in the geographic and jurisdictional space of the city of Clorinda, through which we have been able to determine the neighborhoods with the highest occurrence of the traffic offense and commercialization of illicit drugs and the so-called "hot zones" of concentration of criminal acts related to this scourge that makes a dent especially in youth and in the most vulnerable sectors of society. 


\section{Introducción}

La Geografía del Delito es una sub-disciplina de la Ciencia Geográfica y en particular de la Geografía Urbana, debido a que la delincuencia es esencialmente un fenómeno urbano. Es por ello que el delito debe considerarse como una problemática espacial, ya que los hechos delictivos pueden localizarse en puntos precisos sobre la superficie terrestre (Cardozo et al., 2004).

Los hechos delictivos ocurren principalmente en las ciudades, y es en ellas donde se manifiestan los principales problemas respecto a la seguridad, debiéndose volcar en los espacios urbanos la mayoría de los recursos institucionales que puedan dar respuesta a las disfunciones sociales generadas por la inseguridad (Lahosa, 2002).

La inseguridad es uno de los mayores flagelos con los que deben convivir los ciudadanos. El atractivo urbano -especialmente de las grandes áreas urbanas- ha estado acompañado no sólo por un aumento de la tasa delictiva y de los problemas de seguridad, sino también por un aumento del sentimiento de inseguridad y el miedo al delito de muchos ciudadanos, llevando esto a la reducción de la calidad de vida de las personas (Van Soomeren, 2007).

Pelacchi (2000) considera al delito como una de las problemáticas urbanas más urgentes a resolver, sobre todo en las grandes ciudades, ocupando esta temática un lugar central entre las cuestiones que generan preocupación en las autoridades y en la sociedad.

Para Kessler (2009) el temor al delito constituye una gran incertidumbre, ya que se considera a la seguridad ciudadana como un indicador de calidad de vida, de acuerdo a lo estipulado por la Organización de las Naciones Unidas.

Desde una visión geográfica, este estudio se enfoca por un lado en el análisis de las características de la actividad delictiva de narcotráfico y narcomenudeo, y por otro lado en la distribución espacial de este tipo de ilícitos.

Para ello, la escala de análisis que hemos utilizado, -la ciudad en su conjunto- amerita la posibilidad de considerar a los barrios urbanos como unidades de análisis independientes respecto a la ocurrencia de este tipo de delito, pudiéndose incluso clasificar a los mismos como de alto, medio o bajo nivel de ocurrencia delictiva en lo que respecta al tráfico y comercialización de narcóticos.

Asimismo, dentro de los territorios barriales es posible identificar lugares puntuales donde la ocurrencia de los hechos delictivos supera a la media general de la ciudad, considerándose a esos lugares en particular como puntos calientes o zonas calientes del delito.

La ciudad de Clorinda es la segunda localidad en orden de importancia de la provincia de Formosa, siendo ésta cabecera del departamento Pilcomayo. El Censo Nacional de Población del año 2010 indicaba que en ella residían 52.837 habitantes. En el año 2019 la población estimada se calcula en casi 59.000 habitantes. Su composición poblacional -reflejada en su pirámide de población progresiva de forma triangular o de torre Eiffel- indica una sociedad con una amplia base de niños y jóvenes, una proporcionada población adulta y una cúspide poco desarrollada de adultos mayores.

Localizada en la frontera con la República del Paraguay y cercana a su capital, Asunción, su actividad económica predominante es la comercial, -que la posiciona como una ciudad de función homónima- lo que es típico en una ciudad fronteriza. Frente a Clorinda cruzando el río Pilcomayo se encuentra la localidad paraguaya de Puerto Elsa o Nanawa, localidad que concentra el mayor flujo comercial e intercambio social con la misma. Asimismo una gran parte de sus habitantes son empleados públicos (nacionales, provinciales y municipales) e integrantes de las diferentes fuerzas de seguridad que operan en la cabecera departamental.

Los vecinos clorindenses pueden percibir que el delito ha aumentado dentro de esta localidad en todas sus formas y dimensiones desde un tiempo atrás a la actualidad, por lo que pretendemos geodimensionar la ocurrencia de este fenómeno, especialmente en lo que respecta al delito de narcotráfico y sobre todo a una de sus facetas más visibles: el narcomenudeo.

Como objetivo general nos hemos planteado conocer las diversas modalidades de los hechos delictivos vinculados con el tráfico y comercialización de narcóticos a pequeña y gran escala, mientras que como objetivos específicos por un lado pretendemos localizar espacialmente los mencionados hechos delictivos, y por otro identificar los hot-spot o zonas calientes de este tipo de delitos dentro del ejido urbano de la ciudad de Clorinda. 


\section{Marco teórico}

\subsection{Narcotráfico y narcomenudeo}

Consideramos delito a toda acción o actividad realizada por las personas por fuera del marco regulatorio de la ley penal, con la intención comprobable o el daño de hecho a la vida humana y/o al patrimonio de las personas. Los delitos pueden ser cometidos contra las personas (en el caso que atenten contra la integridad psicofísica o la salud de las mismas), y contra la propiedad y/o los bienes de las personas, sean éstos de personas individuales o propiedad del conjunto de la sociedad. Para ejemplificar, la venta de alcohol y de tabaco es nociva para la salud de las personas, pero no constituye delito, ya que no se encuentran penadas por la ley (Conte et al., 2018).

El narcotráfico y el narcomenudeo son considerados delitos contra las personas, ya que afectan la integridad (salud) física o mental de las mismas.

Como dijimos, se considera delito a toda actividad que se realice fuera del marco de la ley penal. Es por ello que la venta de marihuana en narcomenudeo constituye actualmente un delito, ya que se encuentra penalizada por la ley. En el caso que se legalice la venta minorista de marihuana, (acción que podría seguir a los proyectos de ley presentados para legalizar la tenencia y el consumo de esa substancia) esta actividad dejaría de ser un delito y se constituiría en una actividad comercial informal y/o formal.

Definimos 'narcotráfico' a la producción, el transporte, la distribución y la comercialización de narcóticos a gran escala, llevada a cabo por organizaciones criminales especializadas en dicha actividad. El narcotráfico como negocio económico posee sus fundamentos bien definidos.

En primer lugar, el narcotráfico constituye una verdadera fuente de financiamiento para las actividades criminales complejas, las cuales sin el poder económico del narcotráfico no podrían prosperar y trascender tan abruptamente. Segundo, es importante mirar el deterioro social y económico que el narcotráfico genera en la población, lo que puede ser concebido como un caldo de cultivo para el nacimiento de nuevas actividades ilegales. Y tercero, la consecuente infraestructura criminal del narcotráfico se pone al servicio de otras actividades ilegales, lo cual, en el competitivo y violento mundo de las economías criminales. Les brinda ventajas comparativas de protección mafiosa y reproducción económica. (Pontón, 2013, p.136)

En la Argentina la problemática del narcotráfico es muy compleja. Souto Zavaleta, Delfino y Sarti (2019) describieron acertadamente las deficiencias que en nuestro país poseen las políticas vinculadas a este flagelo y que limitan la lucha contra el mismo.

Frente a la evolución descripta en torno a los indicadores de oferta y demanda de estupefacientes, una serie de ejes problemáticos ha caracterizado la gestión de las políticas de prevención y control del narcotráfico en Argentina en los últimos años: a) una conceptualización del problema desde una retórica belicista con una consiguiente tendencia militarizante; b) la ausencia de un diagnóstico en el diseño e implementación de las políticas, con el agravante de la existencia de profundos errores de diagnóstico; c) una tendencia analíticamente limitada en el análisis de la efectividad de las políticas implementadas y una profunda indiferencia respecto de la consideración del impacto de esas políticas; d) una ausencia de planes y programas ajustados a la realidad local; e) una delegación política de la gestión a las instituciones policiales con altos niveles de autonomía y fragmentación policial en el abordaje del problema y complejas estrategias de vinculación con ciertos organismos extranjeros. Estos ejes, si bien no agotan el posible análisis de las políticas de prevención y control del narcotráfico en nuestro país, constituyen en conjunto importantes limitantes para un abordaje efectivo del problema que, como hemos visto, fue adquiriendo complejidad en los últimos 15 años. (Souto Zavaleta, Delfino y Sarti, 2019, p.73)

Por otra parte definimos 'narcomenudeo' como la venta de narcóticos al detalle, venta minorista o al por menor, llevado a cabo por personas en la vía pública (dealers) o en pequeños lugares de venta denominados 'quioscos' o 'bunkers'. La droga se comercializa tanto en forma ambulatoria como en lugares fijos, en los ya mencionados quioscos o bunkers. Asimismo, puede considerarse también al narcomenudeo como una organización empleada para el suministro de drogas en cantidades pequeñas, cuya finalidad es 
satisfacer las necesidades de los consumidores, siendo éstas comercializadas desde determinados puntos de venta.

El narcomenudeo o comercio de drogas ilícitas en pequeña escala se origina con la prohibición del consumo de drogas y por los intentos de controlar el mismo por razones económicas y médicas.

En la actualidad, el narcomenudeo es un fenómeno que amalgama diversas actividades delictivas cuya finalidad es proveer drogas ilícitas a los consumidores. Tales actividades se realizan en los intersticios de las relaciones sociales, y la dificultad para estudiarlas radica en lo ilícito de las drogas, lo cual fundamenta la persecución que realizan las autoridades públicas y propicia que sus actores prefieran mantener el anonimato. La piedra angular de este fenómeno es una relación de mercado donde un vendedor oferta una mercancía y es interpelado por un comprador que la consume. La variante de las relaciones de mercado que se utiliza es la del menudeo, en la que los compradores son los consumidores del producto; diferenciándose de la relación de narcotráfico en que el comprador, a su vez, venderá la mercancía. En otras palabras, de la cadena de operaciones de mercado que se realizan en el tráfico de drogas ilícitas, el narcomenudeo es el eslabón final del narcotráfico. (Zamudio Angles. 2008, p.1-2)

El narcomenudeo es un fenómeno esencialmente urbano que tiene vasos comunicantes con otros delitos, como ser homicidios vinculados a ajustes de cuentas entre bandas y cruentas disputas por el control territorial para el desarrollo de esa actividad ilegal, o robos cometidos por adictos que precisan el dinero para comprar drogas. (Sangiorgio, 2018).

Según Alvarado (2013) las características del mercado minorista de estupefacientes están entrelazadas a tres aspectos: el primero de ellos referido al punto de venta, que es el lugar en el que se realiza la transacción comercial de pequeñas cantidades de sustancias estupefacientes, el segundo aspecto considera a la monetización como el momento en el que las drogas ilícitas son intercambiadas por dinero (de origen legal o ilícito) o de manera excepcional por algunos bienes y servicios, mientras que el tercer y último aspecto se refiere al consumo como actividad interdependiente con el sistema del tráfico de drogas que mediante la demanda, -que se desarrolla en espacios de uso público o privado, abiertos o cerrados- y que tiene como propósito darle utilidad al producto comprado, del cual los usuarios esperan un efecto estupefaciente para satisfacer una necesidad según el estado de adicción o dependencia.

Para el mencionado autor el narcomenudeo es parte de la cadena del narcotráfico. La misma se compone de cuatro eslabones a saber: La producción, la distribución, la comercialización y el capital circulante.

La producción es el primer eslabón de esta cadena. Para que la producción de droga sea efectiva deben existir tres elementos fundamentales que son los cultivos (marihuana, coca para la elaboración de cocaína), las substancias químicas (precursores químicos) para la elaboración de la droga a granel y una infraestructura de producción a mediana o gran escala (éstas últimas no son necesarias para el caso del cultivo de marihuana).

La distribución es el segundo eslabón, y se lleva a cabo mediante el acopio y la transformación de la droga, la fijación de una ruta de traslado y su posterior transporte.

El tercer eslabón,-la comercialización-es la que deriva en el narcomenudeo. Para que se comercialicen con éxito los estupefacientes los mismos deben estar manufacturados, procediéndose posteriormente al abastecimiento de los diferentes puntos de ventas y a los dealers o vendedores callejeros.

El último eslabón de la cadena del narcotráfico es el capital circulante, que lleva implícito los costos operativos de la operación delictiva, -la inversión en mercadería (drogas) los medios de transporte y otros que hacen a esta actividad- y por último la acumulación de las ganancias obtenidas, muchas veces blanqueadas mediante el lavado de dinero.

La cadena de valor del narcomenudeo como organización delictiva está integrada por los siguientes aspectos:

- Los productos básicos elaborados en el subsistema de producción, como son la cocaína, marihuana y pasta base y los productos sustitutos de origen farmacéutico empleados en la manufactura de las dosis o vendidos al comprador final.

- Los objetivos de la organización del narcomenudeo, -enfocados en la maximizar las gananciasmanteniendo y ampliando el mercado y promocionando la venta y el consumo de drogas. 
- La accesibilidad ofrecida al consumidor en las condiciones de presentación y precio de venta.

- Los procesos de acumulación de capital mediante la diversificación de actividades criminales, que incluyen procesos de territorialización dentro de un espacio social y que a su vez generan las condiciones necesarias para el logro de los objetivos estratégicos de la organización de narcomenudeo.

- Los productos ya transformados, que son esperados en términos de presentación, precio y accesibilidad por el consumidor. El canal de abastecimiento es el flujo de las sustancias mediante el proveedor de los productos básicos, la manufacturación (transformación) de los mismos, el vendedor al detalle (dealer), y el comprador o usuario final (Alvarado, 2013).

El cannabis tiene una ventaja que lo hace más rentable sobre el clorhidrato de cocaína, aunque esta última posee mayor precio en el mercado de estupefacientes. Su producción es menos costosa; ya no se requiere de refugios ocultos para producirla, ni traficar precursores químicos -cada vez más controlados- y en su cadena de elaboración y distribución se emplea menos mano de obra, lo que reduce en gran medida sus costos de producción (Sangiorgio, 2019).

Debemos destacar que al igual que en la capital formoseña, quienes se dedican a proveer estupefacientes al circuito del narcomenudeo en la ciudad de Clorinda no conforman verdaderas organizaciones criminales, sino que son distribuidores mayoristas individuales que proveen a los dealers minoristas, por lo que todavía no existen procesos de territorialización criminal como sí existen en otras localidades argentinas (como ser el caso de algunas ciudades del conurbano bonaerense o Rosario (Santa Fe) donde las bandas de narcotraficantes pelean entre sí por los espacios de venta en las villas y sus áreas de influencia. (Conte et al., 2018)

En estos espacios urbanizados sí existe una lucha a sangre y fuego protagonizada por las bandas narcos en los barrios más postergados para instalar bunkers o kioscos de venta de drogas al menudeo (Klipphan, 2018).

Al respecto existen trabajos como el de Gañan (2017) donde este autor analiza en su tesina de licenciatura la situación particular de la ciudad de Rosario y de una banda delictiva de narcotraficantes denominada Los Monos.

La Tabla 1 nos muestra la cadena del narcotráfico con sus diferentes componentes.

Tabla 1. Cadena del narcotráfico.

\begin{tabular}{|c|c|c|c|}
\hline \multirow{4}{*}{ NARCOTRÁFICO } & PRODUCCIÓN & $\begin{array}{c}\text { CULTIVOS } \\
\text { SUBSTANCIAS QUÍMICAS } \\
\text { INFRAESTRUCTURA }\end{array}$ & \\
\hline & DISTRIBUCIÓN & $\begin{array}{c}\text { ACOPIO } \\
\text { TRANSFORMACIÓN } \\
\text { RUTA } \\
\text { TRANSPORTE }\end{array}$ & MICROTRÁFICO \\
\hline & COMERCIALIZACIÓN & $\begin{array}{c}\text { MANUFACTURA } \\
\text { ABASTECIMIENTO } \\
\text { PUNTOS DE VENTA }\end{array}$ & NARCOMENUDEO \\
\hline & CAPITAL & $\begin{array}{c}\text { COSTOS OPERATIVOS } \\
\text { INVERSIÓN } \\
\text { ACUMULACIÓN }\end{array}$ & \\
\hline
\end{tabular}

Fuente: Policía Nacional. Dirección de Inteligencia Policial. Centro de Inteligencia Prospectiva, 2012. Recuperado de https://www. odc.gov.co/Portals/1/Docs/oferta/FICHA-MICROTRAFICO-NARCOMENUDEO_oct_2013.pdf

\section{Metodología de trabajo}

Podemos determinar la relación existente entre el espacio y el delito analizando la cantidad o número de delitos concretos registrados y su distribución espacial. Dentro del plano objetivo, la Geografía del Delito o Geografía del Crimen analiza los patrones de distribución espacial de la ocurrencia delictiva en un determinado espacio geográfico.

Para confeccionar este artículo utilizamos datos obtenidos de cuatro portales digitales clorindenses (Clorinda al día, Crónicas de Clorinda, Central de Noticias Clorinda y Frontera), como así también del portal digital oficial de la Policía de la Provincia de Formosa. La recolección de datos se llevó a cabo mediante una planilla donde se consignó la información necesaria para la ejecución de la investigación (clasificación, tipo, modalidad, dirección y horario de ocurrencia de los delitos). 
Asimismo, hemos obtenido del análisis de la información periodística datos que hacen a las características de este delito, como ser la escala de la venta de narcóticos (si es venta al detalle o minorista o tráfico de drogas a mayor escala) y el tipo de substancia ilícita (marihuana, cocaína u otras).

El período de recolección de datos fue entre enero de 2017 y diciembre de 2019, es decir un período de tres (3) años. La escala de análisis aplicada a este trabajo es urbana o local, ya que se trabajó con datos de toda la ciudad de Clorinda. La información periodística fue suministrada a los medios por una fuente confiable, ya que la información sobre delitos es brindada a los periódicos locales (por lo menos en gran parte) por la Policía de la Provincia de Formosa.

En lo que respecta a las representaciones cartográficas, estas son el resultado del procesamiento y análisis de los datos obtenidos, ya que en este tipo de trabajos se utilizan bases de datos que se pueden aplicar a sistemas de información geográfica para confeccionar mapas delictivos. En nuestro caso en particular, hemos elegido volcar la cartografía temática sobre sendos planos de la ciudad de Clorinda especialmente confeccionados para tal fin.

\section{Resultados}

\subsection{El área de estudio}

Respecto al área de estudio, (Guzmán, 1999) describe en su tesina de licenciatura que en lo que concierne a su situación y a su sitio, la ciudad de Clorinda está localizada en la posición geográfica $25^{\circ} 17^{\prime}$ $29^{\prime \prime}$ latitud sur y $57^{\circ} 43^{\prime} 06^{\prime \prime}$ longitud oeste sobre la ribera derecha del río Pilcomayo, a unos 10 kilómetros de su desembocadura en el río Paraguay.

Limita al norte y al este con la República del Paraguay, cuya frontera comparte con la localidad paraguaya de Puerto Elsa, (Nanawa) encontrándose a su vez en una situación geográfica muy cercana la capital de ese país, Asunción.

A Clorinda se puede acceder mediante la ruta nacional $\mathrm{N}^{\circ} 11$, que la conecta a Formosa capital por el sur y a la localidad paraguaya de Puerto Falcón por el norte y a través de la ruta nacional $\mathrm{N}^{\circ}$ 86, que discurre hacia el oeste del territorio provincial y que la integra a las localidades formoseñas de Laguna Blanca y General Belgrano, entre las más importantes.

Por el sector norte de la ciudad discurre el riacho Porteño (autóctono), que desemboca en el río Pilcomayo (alóctono) que, como ya mencionamos, desemboca a su vez en el río Paraguay (alóctono), todos ellos cursos de agua de régimen irregular y alimentación pluvial.

La ciudad está localizada sobre un relieve de llanura conformado por depósitos fluviales, palustres y lacustres, con una cota topográfica de 66 metros sobre el nivel del mar (SNM), poseyendo este tipo de relieve una escasa pendiente de sentido NO-SE (entre $0,1 \%$ y $0,2 \%$ ) que discurre hacia el curso fluvial principal.

Los suelos arcillo- limosos poseen características hidromórficas y han sido en buena parte producto de una gran actividad biológica en la región.

Su clima se caracteriza por ser cálido subtropical sin estación seca, con un promedio pluviométrico anual de 1100 milímetros y temperaturas medias anuales que rondan los $23^{\circ} \mathrm{C}$. Los vientos predominan del sector norte y NE, siendo los mismos cálidos y húmedos.

La ciudad se localiza en un bioma de sabana parque, -con predominio de palmares, pastizales, pajonales y bosques en galería, -además de isletas de bosque o monte fuerte- dentro del Parque Chaqueño Oriental.

Visualizamos el área de estudio en la imagen satelital de la Figura 1. 
Figura 1. Área de estudio: situación y sitio de la ciudad de clorinda.

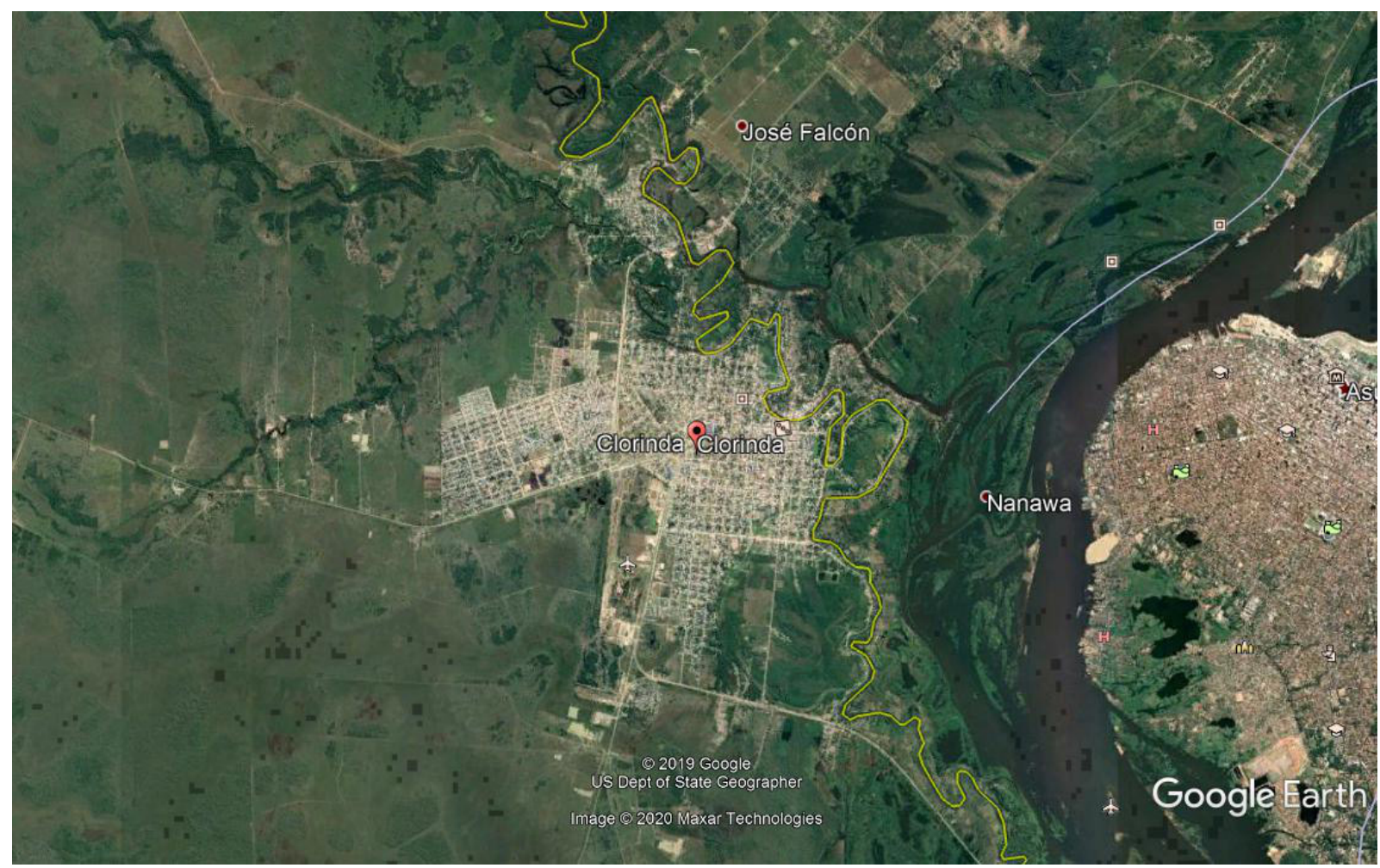

Fuente: Imagen satelital Google Earth. Año 2019.

\subsection{Características del narcotráfico y del narcomenudeo en la ciudad de Clorinda}

Para caracterizar este tipo de delito en la ciudad de Clorinda debemos diferenciar la escala de comercialización de los narcóticos, ya que como expresamos oportunamente, consideramos narcotráfico a la comercialización de estupefacientes a gran escala, y narcomenudeo a la venta al detalle de los mismos.

Tanto el narcotráfico como el narcomenudeo se manifiestan en Clorinda, con la salvedad que en la ciudad misma existe predominancia de delitos relacionados con la venta minorista de drogas y con lugares de acopio de la misma, mientras que el tráfico a gran escala de estas sustancias ilícitas se manifiesta en menor escala dentro de la ciudad.

En términos generales, los alucinógenos que ingresan a nuestro país por los diversos pasos localizados en la ciudad de Clorinda y sus adyacencias provienen de la República del Paraguay y se desplazan por las rutas nacionales que conectan esta localidad con Formosa capital y el interior provincial.

Existen a la vera de estas rutas nacionales puestos de control de las fuerzas de seguridad argentinas (Gendarmería Nacional, Prefectura Naval Argentina, Aduana, Policía de la Provincia de Formosa) que han decomisado en numerosas oportunidades cargamentos de estupefacientes a gran escala.

Sobre la ruta nacional $N^{\circ} 86$, que conecta a Clorinda con el interior provincial (Laguna Naick- Neck, Laguna Blanca, Misión Tacaaglé, General Belgrano, General Güemes, San Martín II, Posta Cambio Zalazar) entre las localidades más importantes, en el puesto de control de Gendarmería Nacional "Docentes Argentinos" hemos contabilizado 7 decomisos de marihuana, de acuerdo a la información de los periódicos locales.

Asimismo, el puesto de control "Fermín Rolón" de Gendarmería Nacional, localizado a la vera de la ruta nacional $\mathrm{N}^{\circ} 11$ que une Clorinda con la ciudad capital, Formosa, ha realizado (siempre según la información periodística) unos 57 decomisos de drogas, sobre todo marihuana y cocaína y en algunos casos éxtasis.

En el paso fronterizo sobre el río Pilcomayo denominado popularmente "Puente Loyola" la Aduana Argentina ha realizado unos 19 decomisos de drogas a gran escala, especialmente marihuana. Este complejo aduanero se encuentra localizado dentro del ejido urbano de la ciudad de Clorinda, -más precisamente sobre la ruta nacional $\mathrm{N}^{\circ} 11$ - entre los barrios Porteño Norte y Porteño Sur, por lo que consideramos los delitos de narcotráfico ocurridos en el mismo como parte de los hechos delictivos llevados a cabo en 
la cabecera del departamento Pilcomayo, más allá que no los contabilicemos dentro de ninguno de los barrios mencionados.

Por último, más allá del complejo aduanero de San Ignacio de Loyola pero dentro de los límites del ejido urbano de la ciudad de Clorinda, se han decomisado unos 29 cargamentos de estupefacientes (sobre todo marihuana) que por su volumen pueden ser considerados como delitos de narcotráfico, tanto en lugares de acopio como en tránsito, y cuyos decomisos fueron llevados a cabo por la Prefectura Naval Argentina y por la División Drogas Peligrosas de la Policía de la Provincia de Formosa.

Por otro lado y como ya expresamos, el narcomenudeo es uno de los eslabones de la cadena del narcotráfico, es decir del comercio ilegal de drogas tóxicas en grandes cantidades. El proceso del narcotráfico comienza por el cultivo de las sustancias o la fabricación de los narcóticos, continúa con la distribución y comercialización mediante las diversas organizaciones ilícitas (carteles), -especializadas en las diferentes partes de la cadena- y finaliza con la acumulación de la riqueza obtenida mediante esta actividad criminal.

En la ciudad de Clorinda existe una dualidad entre la venta y el consumo. Muchos adictos se convierten en dealers para poder solventarse su propio consumo. Claro está que esta situación no se presenta en todos los casos, aunque sí en la mayoría de ellos.

De similar manera que en la ciudad de Formosa, la mayoría de los dealers son jóvenes varones pertenecientes a clases sociales desfavorecidas, con escasa educación formal, que toman esta actividad ilícita en muchos casos como salida laboral ante la falta de trabajo. Muchos de estos jóvenes provienen de familias desintegradas o en procesos de desintegración o conflictivas. (Conte et al., 2018)

Esta generalización resulta de conversaciones informales mantenidas con jóvenes dealers en algunos barrios clorindenses, a quienes se ha preguntado respecto a su situación familiar, nivel de instrucción, situación laboral, condición económica, etc. Cabe aclarar que la totalidad de dealers consultados se dedica a la venta de cocaína y de marihuana.

Por otro lado se llevaron a cabo indagaciones sobre a la venta y consumo de drogas en algunos lugares de concentración de jóvenes, como ser los boliches bailables de Clorinda. En este caso se preguntó a algunos concurrentes asiduos a estos locales bailables al respecto.

Con estas averiguaciones se pudo constatar que más allá de las substancias narcóticas ya mencionadas, no se detectó la presencia de otras drogas como ser narcóticos de diseño o sintéticos dentro del casco urbano. Los cargamentos de éxtasis provenientes de la República del Paraguay decomisados por Gendarmería Nacional en el puesto de control Fermín Rolón al sur de la ciudad, estaban de paso por Clorinda y evidentemente tenían como destino las grandes urbes del sur del país.

Del análisis de la información obtenida entre los años 2017 y 2019 de los periódicos digitales clorindenses Frontera, Clorinda al día, Crónicas de Clorinda y Central de Noticias Clorinda, como así también del portal oficial de la Policía de la Provincia de Formosa, pudimos diferenciar dos formas de venta al detalle de narcóticos a saber:

a. La venta callejera: llevada a cabo por los jóvenes dealers mediante la comercialización de las substancias alucinógenas en la vía pública. Estos jóvenes por un lado tienen una clientela fija de consumidores, y por otro lado ofrecen su mercadería a otros jóvenes que todavía no se constituyeron en clientes fijos. Esta venta callejera es territorial, generalmente a escala barrial y en determinados sectores de un barrio en particular. Predomina aquí la comercialización de marihuana y en menor medida de cocaína. También se ha podido constatar mediante la información periodística la venta de substancias estupefacientes en cercanías de colegios y locales bailables.

b. La venta en puntos fijos domiciliarios: en este caso la comercialización ilegal de estupefacientes se realiza en domicilios fijos, denominados bunkers o kioscos, donde los adictos concurren a adquirir las substancias alucinógenas. También existe en estos lugares un predominio de venta de marihuana y cocaína en menor medida. A veces la venta domiciliaria es una actividad comercial familiar, posiblemente producto de la crisis económica y de la falta de trabajo.

Desde el punto de vista institucional, el Gobierno de la provincia de Formosa definió la lucha contra el narcocrimen en dos aspectos: el aspecto legal y el aspecto operacional. Dentro del aspecto legal se promulgó la Ley $\mathrm{N}^{\circ} 1.627$ referida al narcotráfico y al narcomenudeo.

Esta ley es muy positiva en cuanto habilita por primera vez un fuero especial para esta temática y se crean juzgados nuevos para tal fin, como el de la ciudad de Formosa, - ya operativo- y los futuros juzgados de las localidades de Las Lomitas y Clorinda. 
Operacionalmente, la ciudad de Formosa es sede del Juzgado del Narcocrimen, es decir la oficina judicial con competencia en este tipo de delito. Este Juzgado especializado tiene como finalidad por un lado atacar el narcomenudeo e intervenir e interceptar a las personas que venden la droga a los consumidores y por otro trabajar en cuanto a la rehabilitación y recuperación de los mismos, tanto en su forma incipiente como en estado de adicción.

En esta línea, la norma impone un trabajo coordinado del Juzgado con el Ministerio de la Comunidad y el Ministerio de Desarrollo Humano, ya que este juzgado especializado en narcomenudeo permitirá un abordaje integral de la problemática, que incluye atender a las personas que se encuentran sumidos en el flagelo del consumo, es decir su tratamiento médico, desintoxicación y contención. (Conte et al., 2018)

En términos generales, podemos precisar que la droga consumida en la ciudad de Clorinda ingresa proveniente de la República del Paraguay por la zona ribereña del río Pilcomayo, curso de agua que separa la cabecera departamental de la localidad fronteriza de Puerto Elsa (Nanawa).

\subsection{Dimensión del narcotráfico y del narcomenudeo en la ciudad de Clorinda}

Para analizar y comprender la dimensión de los delitos de narcotráfico y narcomenudeo dentro de la ciudad de Clorinda, debemos contextualizarlo dentro de la ocurrencia del delito en general en la cabecera departamental.

Según la información obtenida de los periódicos locales en el período comprendido entre los años 2017 y 2019, en toda la ciudad de Clorinda sucedieron durante ese período 642 delitos de toda índole, de los cuales 267 fueron contra las personas y 375 contra la propiedad o los bienes de las personas.

De los 375 delitos cometidos contra la propiedad y/o bienes de las personas, 151 correspondieron a hurtos, 203 a robos (con sus correspondientes grados de tentativa) 10 a casos de vandalismo, 6 a estafas, 3 a usurpación de inmuebles y 2 a reducción de bienes robados.

De los 267 delitos cometidos contra las personas, unos 150 fueron hechos relacionados con el narcotráfico y narcomenudeo, (excluyendo los decomisos de la Aduana en el complejo San Ignacio de Loyola) lo que constituye el 56,2\% de los mismos. Esto representa asimismo el 23,4\% del total de delitos cometidos en toda la ciudad en ese período. El resto de los delitos contra las personas fueron referidos al contrabando, (33 hechos) a agresiones y amenazas, (48 casos) a homicidios y sus grados de tentativa, (19 hechos) a abuso sexual (11 delitos) y a portación ilegal de armas (6 casos).

Dentro de los delitos de narcotráfico, 120 (80\%) de ellos fueron por narcomenudeo y 30 (20\%) por tráfico de estupefacientes a mayor escala.

Si tomamos en cuenta los delitos de narcomenudeo, de acuerdo a la información periodística 62 de esos delitos correspondieron a la comercialización minorista de marihuana, 49 a la venta de cocaína y 9 delitos de ventas mixtas (cocaína y marihuana).

En cambio, teniendo en cuenta los delitos de narcotráfico mayorista, 30 decomisos fueron cargamentos de marihuana, 3 de cocaína y 1 mixto.

Como ya especificamos oportunamente, uno de los objetivos de este trabajo es el análisis de la distribución espacial del delito de tráfico de narcóticos. Para llevar esto a cabo utilizamos una escala de análisis barrial, es decir tomamos en cuenta los límites jurisdiccionales de cada barrio en particular de la ciudad de Clorinda.

La Tabla 2 nos muestra el número de delitos registrados en los periódicos digitales locales Frontera, Clorinda al día, Crónicas de Clorinda y Central de Noticias Clorinda, como así también en el portal oficial de la Policía de la Provincia de Formosa, referidos al tráfico y comercialización de estupefacientes en los barrios clorindenses durante el período 2017-2019. 
Tabla 2. Número de delitos de narcotráfico y narcomenudeo registrados por barrio. Período 2017-2019. (Excluye los decomisos de la Aduana en el Complejo Puente Loyola).

\begin{tabular}{|c|c|c|c|c|c|}
\hline BARRIOS & $\mathbf{N}^{\circ}$ & BARRIOS & $\mathbf{N}^{\circ}$ & BARRIOS & $\mathbf{N}^{\circ}$ \\
\hline 25 DE MAYO & 22 & SANTA MARÍA & 3 & SIN DATOS & 2 \\
\hline CENTRO & 20 & PEDRO MONTOYA & 3 & 29 DE SEPTIEMBRE & 1 \\
\hline LIBERTAD & 13 & MANUEL BELGRANO & 3 & SAN CAYETANO & 1 \\
\hline $1^{\circ}$ DE MAYO & 13 & 8 DE ABRIL & 3 & AGUA POTABLE & 1 \\
\hline PORTEÑO NORTE & 11 & S. VICENTE PAULS & 2 & SAN LUIS & 1 \\
\hline INDEPENDENCIA & 10 & TOBA & 2 & ALTO & 1 \\
\hline ACA & 6 & ITATÍ & 2 & COOPERATIVA & 1 \\
\hline EVA PERÓN & 5 & JUAN J. BOGARÍN & 2 & EUCLIDES INSFRAN & 1 \\
\hline JUAN D. PERÓN & 5 & 6 DE ENERO & 2 & STA. MARG. CARTONÁ & 1 \\
\hline SAN MIGUEL & 5 & PORTEÑITO & 2 & 7 DE MAYO & 1 \\
\hline PORTEÑO SUR & 3 & 2 DE AGOSTO & 2 & TOTAL & 150 \\
\hline
\end{tabular}

Fuente: elaboración propia con datos de los portales digitales Clorinda al día, Crónicas de Clorinda, Central de Noticias Clorinda, Frontera y el portal oficial de la Policía de la Provincia de Formosa.

Estas cifras nos indican que el barrio 25 de Mayo acumula más del 14,7\% de los delitos de narcotráfico y narcomenudeo cometidos en la cabecera departamental. Los barrios Centro, Libertad, $1^{\circ}$ de Mayo, Porteño Norte e Independencia lo siguen en número de hechos delictivos de este tipo.

En el plano correspondiente a la Figura 3 podemos visualizar a los barrios 25 de Mayo y Centro que poseen el tono más oscuro de color, lo que refleja el impacto de los mismos en lo referido a la ocurrencia de delitos de narcotráfico y narcomenudeo dentro de la ciudad de Clorinda. Estos barrios ocuparían un primer escalón en lo que respecta a delitos de esta índole.

Además de los barrios antedichos, podemos apreciar en este plano los barrios Libertad, $1^{\circ}$ de Mayo, Porteño Norte e Independencia, donde ocurrieron también una considerable cantidad de hechos delictivos referidos a narcóticos. Estos barrios se posicionarían en un segundo escalón en lo que hace a la ocurrencia de delitos de este tipo.

El resto de los barrios de la ciudad de Clorinda presenta una cantidad relativamente baja de delitos vinculados a tráfico y venta minorista de estupefacientes, por lo que los ubicaríamos en un tercer escalón de ocurrencia en este tipo de delitos.

Lamentablemente la Municipalidad de la ciudad de Clorinda no posee estimaciones del número de habitantes por barrio, siendo la única información poblacional disponible la de los radios censales. Como muchas veces los límites de los radios censales no concuerdan con los límites jurisdiccionales de los barrios, no pudimos calcular las tasas de delito barriales, por lo que optamos por trabajar con los números absolutos de delitos registrados por barrio, calculando sí la tasa delictiva de toda la ciudad en el período estudiado.

Una tasa de delitos se calcula mediante el cociente entre el número de delitos de cada año y la población de dicho año, multiplicado por 10.000 o 100.000, según sea la población de la ciudad estudiada.

La tasa de delitos de narcotráfico y narcomenudeo de la ciudad de Clorinda se calculó en base a la población estimada por la Dirección Provincial de Estadísticas y Censos para los años 2017, 2018 y 2019 , estimación que tuvo en cuenta la población del año 2010 (52.837 habitantes según el Censo Nacional de Población y Vivienda).

La misma es de 8,6 delitos cada 10.000 habitantes. Esta tasa referencia el promedio de las tasas resultantes de cada año analizado.

En la Tabla 3 y la Figura 2 podemos ver la evolución de las tasas delictivas referidas a narcotráfico y narcomenudeo en el período estudiado. 
Tabla 3. Evolución de la tasa de delitos de narcotráfico y narcomenudeo en la ciudad de clorinda. Período 2017-2019. (Excluye los decomisos de la Aduana en el Complejo Puente Loyola)

\begin{tabular}{|c|c|c|c|}
\hline AÑO & $\begin{array}{c}\mathbf{N}^{\circ} \text { DE DELITOS } \\
\text { VINCULADOS CON DROGAS }\end{array}$ & $\begin{array}{c}\text { NÚMERO ESTIMADO DE } \\
\text { HABITANTES }\end{array}$ & $\begin{array}{c}\text { TASA DELICTIVA } \\
\text { ( } \mathbf{N}^{\circ} \text { delitos vinculados con } \\
\text { drogas cada 10.000 Hab.) }\end{array}$ \\
\hline 2017 & 50 & 57.374 & 8,7 \\
\hline 2018 & 45 & 58.022 & 7,8 \\
\hline 2019 & 55 & 58.670 & 9,4 \\
\hline
\end{tabular}

Fuente: elaboración propia con datos de los portales digitales Clorinda al día, Crónicas de Clorinda, Central de Noticias Clorinda, Frontera, el portal oficial de la Policía de la Provincia de Formosa y de la Dirección Provincial de Estadísticas y Censos.

Figura 2. Evolución de la tasa de delitos de narcotráfico y narcomenudeo en la ciudad de clorinda. Período 2017-2019. (Excluye los decomisos de la Aduana en el Complejo Puente Loyola)

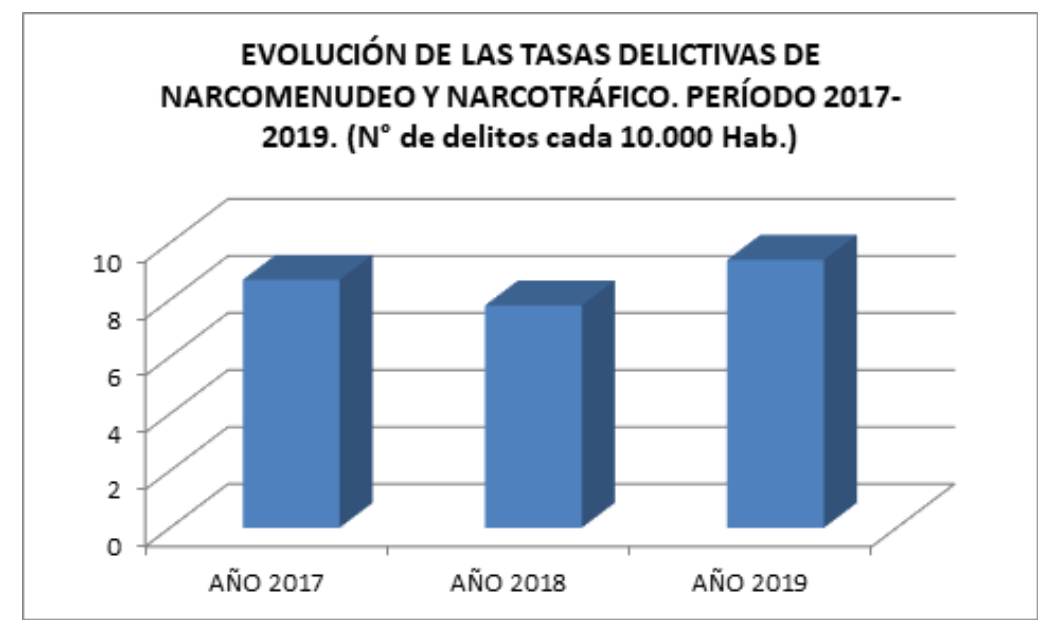

Fuente: elaboración propia con datos de los portales digitales Clorinda al día, Crónicas de Clorinda, Central de Noticias Clorinda, Frontera, el portal oficial de la Policía de la Provincia de Formosa y de la Dirección Provincial de Estadísticas y Censos.

El número absoluto de delitos por barrio en la ciudad de Clorinda lo podemos apreciar en el plano correspondiente a la Figura 3. 
Figura 3. Número de delitos referidos a narcotráfico y narcomenudeo ocurridos en los diferentes barrios de la ciudad de clorinda en el período 2017-2019. (Excluye los decomisos de la Aduana en el Complejo Puente Loyola).

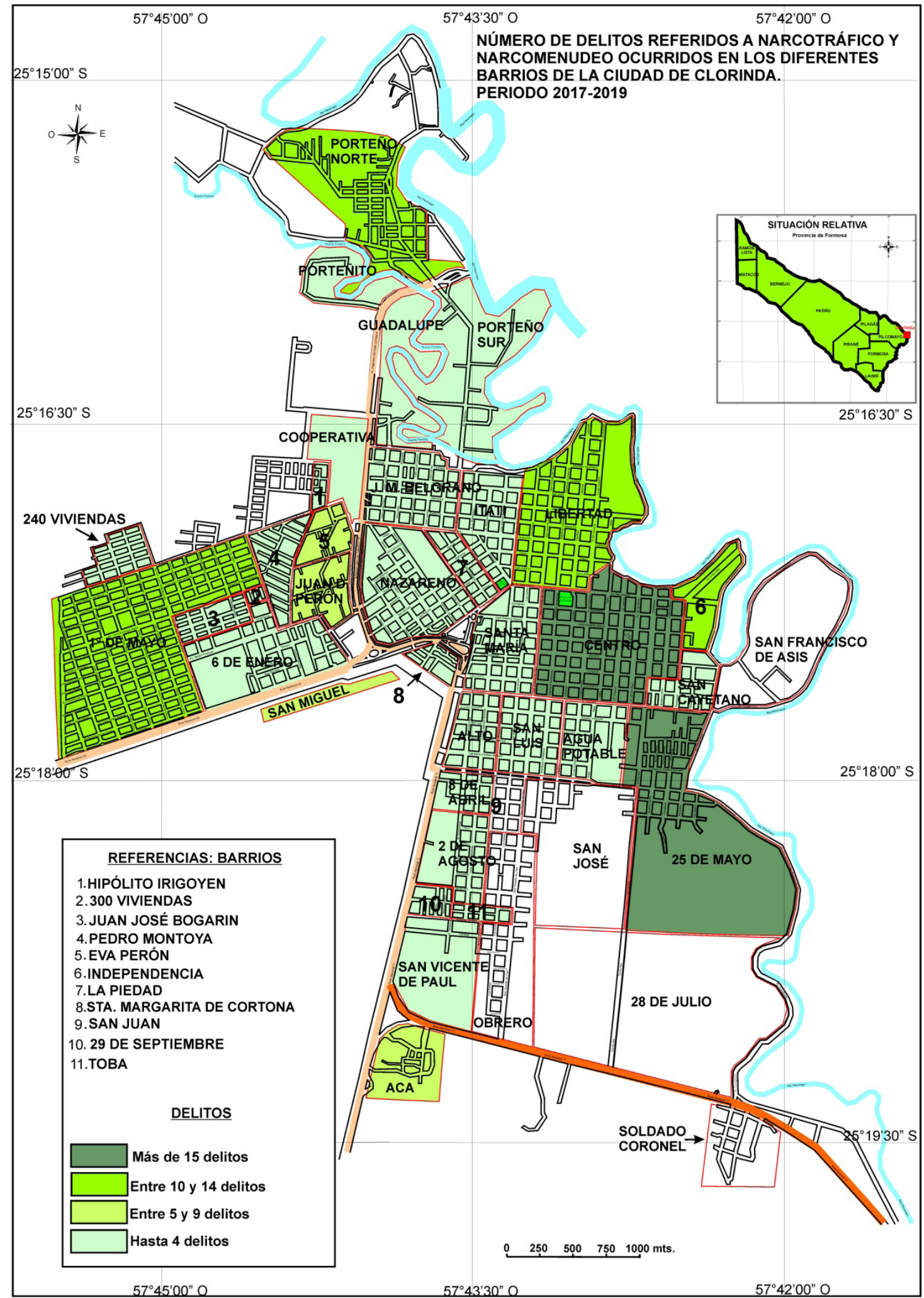

Fuente: elaboración propia con datos de los portales digitales Clorinda al día, Crónicas de Clorinda, Central de Noticias Clorinda, Frontera y el portal oficial de la Policía de la Provincia de Formosa.

También podemos analizar la cantidad de delitos de narcotráfico y narcomenudeo que se cometieron en cada una de las jurisdicciones policiales existentes en la ciudad de Clorinda. Cada una de ellas integra a varios barrios de la esta localidad agrupados por sectores urbanos.

Existen en Clorinda cuatro jurisdicciones policiales a saber: La comisaría Oficial Sub-inspector Idelfonzo Vera, (barrios localizados en el sector oriental y sud-oriental de la ciudad) la sub-comisaría $1^{\circ}$ de Mayo, (barrios del sector occidental) la sub-comisaría Territorios Nacionales (sectores barriales centrales) 
y el destacamento El Porteño, cuya jurisdicción abarca los asentamientos barriales ubicados al norte del ejido urbano clorindense.

La Tabla 4 nos indica la cantidad de delitos de esa índole en cada jurisdicción policial.

Tabla 4. Número de delitos de narcotráfico y narcomenudeo por jurisdicción policial. Período 2017-2019. (Excluye los decomisos de la Aduana en el Complejo Puente Loyola)

\begin{tabular}{|c|c|c|}
\hline JURISDICCIONES POLICIALES & $\begin{array}{c}\mathbf{N}^{\circ} \text { DE DELITOS } \\
\text { VINCULADOS CON } \\
\text { DROGAS }\end{array}$ & $\begin{array}{c}\text { \% DE DELITOS } \\
\text { VINCULADOS CON } \\
\text { DROGAS }\end{array}$ \\
\hline COMISARÍA SUBINSPECTOR IDELFONZO VERA & 90 & $60,0, \%$ \\
\hline SUBCOMISARÍA 1 ${ }^{\circ}$ DE MAYO & 22 & $14,7 \%$ \\
\hline SUBCOMISARÍA TERRITORIOS NACIONALES & 20 & $13,3 \%$ \\
\hline DESTACAMENTO EL PORTEÑO & 16 & $10,7 \%$ \\
\hline SIN DATOS & 2 & $1,3 \%$ \\
\hline TOTAL & 150 & $100 \%$ \\
\hline
\end{tabular}

Fuente: Elaboración propia con datos de los portales digitales Clorinda al día, Crónicas de Clorinda, Central de Noticias Clorinda, Frontera y el portal oficial de la Policía de la Provincia de Formosa.

Podemos observar que el 60\% de los delitos de narcotráfico y narcomenudeo cometidos en la ciudad de Clorinda (90) en el período estudiado ocurrieron en la jurisdicción de la Comisaría Sub-inspector Idelfonzo Vera, la más importante y que comprende entre otros al barrio Centro (incluyendo al microcentro y al macrocentro). En las otras tres jurisdicciones policiales se reportó la ocurrencia de 58 hechos delictivos, correspondientes al 38,7\% de los delitos registrados referidos a narcóticos. Sobre 2 delitos (1,3\%) no se tienen datos.

Los barrios que componen cada jurisdicción policial y el número de delitos referidos a narcotráfico y narcomenudeo cometidos en cada una de ellas, los podemos visualizar en el plano correspondiente a la Figura 4. 
Figura 4. Distribución de los delitos de narcotráfico y narcomenudeo en cada jurisdicción policial de la ciudad de clorinda. Período 2017-2019. (Excluye los decomisos de la Aduana en el Complejo Puente Loyola)

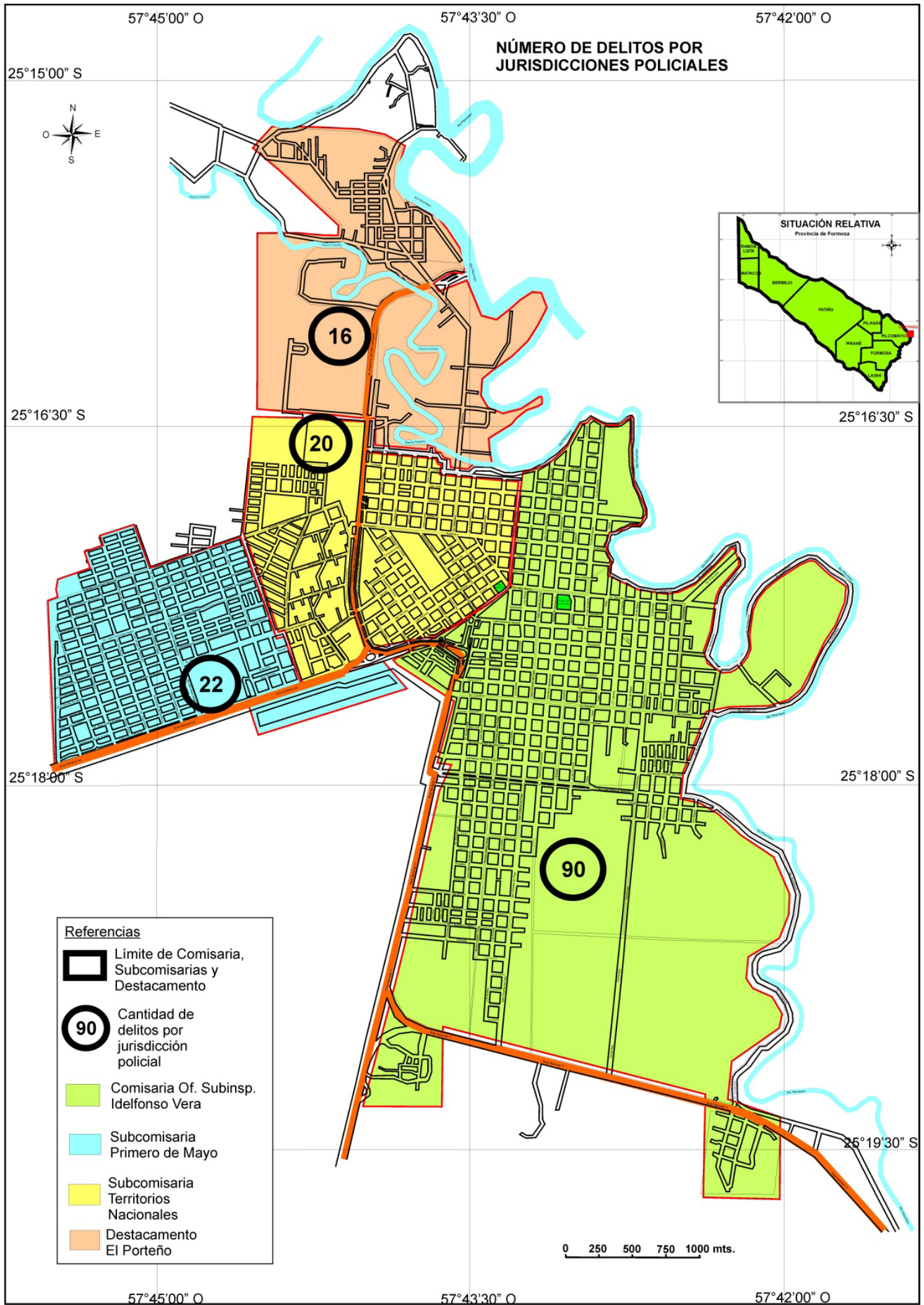

Fuente: elaboración propia con datos de los portales digitales Clorinda al día, Crónicas de Clorinda, Central de Noticias Clorinda, Frontera y el portal oficial de la Policía de la Provincia de Formosa.

Como ya expresamos con anterioridad, otro de los objetivos de este artículo es la localización de los denominados puntos calientes del delito de tráfico de narcóticos. Definimos puntos calientes como los lugares precisos donde se producen mayor cantidad de hechos delictivos dentro de un determinado espacio geográfico. Estos puntos calientes pueden expandirse espacialmente y conformar zonas precisas, por lo cual estaríamos hablando de "zonas calientes" del tráfico y comercialización de estupefacientes. 
El término "hot spot" o punto caliente se utiliza dentro del campo de la criminología para georeferenciar las zonas donde se cometen mayor número de delitos. Según Eck (2005) un hot spot es lugar geográfico que supera el número medio de eventos delictivos o en el que el riesgo de ser víctima de un delito es superior a la media y que a su vez ofrece una representación gráfica muy específica y fácilmente interpretable.

Un hallazgo registrado desde los inicios de la geografía del crimen como área científica de estudio y que mantiene su validez a la fecha es la tendencia que muestra la actividad criminal a concentrarse geográficamente. Recientemente a estas concentraciones se les ha llamado hot spots. Definido de la manera más simple, un hot spot es el área geográfica que tiene la mayor concentración de actividad criminal entre las áreas vecinas, atendiendo a la mayor concentración de incidencia criminal, se puede designar como tal a aquella área que está por encima del promedio. (Vilalta Perdomo, 2009, p.52)

Espacialmente, dentro de la ciudad de Clorinda podemos localizar tres sectores en particular que conforman los denominados "puntos o zonas calientes del narcotráfico y narcomenudeo" y que son los siguientes:

a. El complejo aduanero San Ignacio de Loyola, ubicado sobre la ruta Nacional $\mathrm{N}^{\circ} 11 \mathrm{y}$ localizado entre los barrios Porteño Norte y Porteño Sur, donde se decomisaron grandes cantidades de estupefacientes (sobre todo marihuana). En este caso los narcóticos son transportados en autobuses de larga distancia, en camiones e incluso en automóviles particulares. En su totalidad corresponden a delitos de narcotráfico, ya que este sector aduanero no es propicio para la venta al detalle por la fuerte presencia de fuerzas de seguridad que controlan la frontera.

b. El sector localizado entre la pasarela de la Amistad y la terminal de ómnibus de Clorinda, en el microcentro clorindense. Comprende parte de los barrios Centro e Independencia. En esta área se concentran tanto hechos de tráfico de drogas al por mayor como de narcomenudeo o venta de estupefacientes al detalle. Aquí predomina la venta callejera en el caso de la comercialización al detalle.

c. El barrio 25 de Mayo, donde predominan mayoritariamente hechos delictivos vinculados al narcomenudeo, sobre todo en lo que respecta a la venta domiciliaria o en bunkers de estupefacientes. Al ser un sector extenso, más que un punto caliente debemos considerarlo como un área caliente. En este barrio se han detectado bunkers dedicados tanto a la venta de marihuana como de cocaína, y en algunos casos de ambos a la vez.

La localización espacial de los hot spot o puntos calientes de los delitos relacionados a estupefacientes en la ciudad de Clorinda la podemos apreciar en el plano correspondiente a la Figura 5. 
Figura 5. Distribución espacial de los delitos de narcotráfico y narcomenudeo en la ciudad de clorinda período 2017-2019. (Incluye los decomisos de la Aduana en el Complejo Puente Loyola)

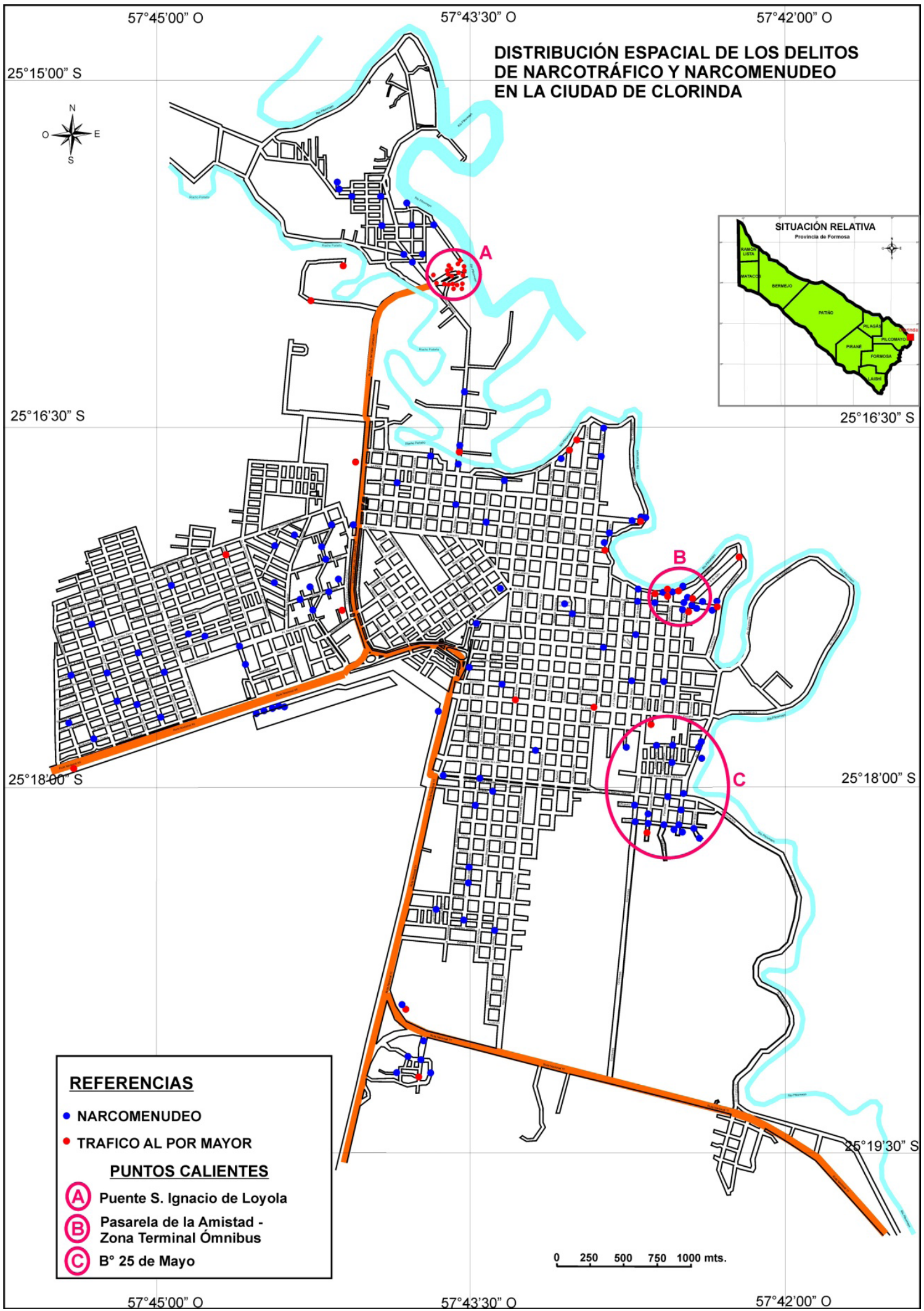

Fuente: elaboración propia con datos de los portales digitales Clorinda al día, Crónicas de Clorinda, Central de Noticias Clorinda, Frontera y el portal oficial de la Policía de la Provincia de Formosa.

Respecto al horario de ocurrencia de este tipo de delitos, no se ha determinado que exista una franja horaria preferida para delinquir, ya que si bien en el horario nocturno (20 hs. a 06 hs.) se cometieron el 40,3\% de los delitos relacionados con narcóticos, un porcentaje similar de hechos delictivos (34,9\%) fueron cometidos durante la mañana (06 a 12 horas) y el 20,8\% de los delitos de narcotráfico y narcomenudeo fueron llevados a cabo durante la tarde. Sobre el $4 \%$ de los delitos de tráfico y comercialización de estupefacientes 
no se tienen datos. Estos porcentajes han sido calculados en base a la información que respecto al horario de ocurrencia de los delitos de narcotráfico y narcomenudeo nos brindaron los periódicos digitales locales ya mencionados y el portal oficial de la Policía de la Provincia de Formosa.

Estos horarios delictivos se no se correlacionan con el resto de los delitos tanto contra la propiedad como contra las personas en todas sus modalidades, ya que en términos de la ocurrencia de los delitos en general, el horario preferido para delinquir es el nocturno.

Veamos al respecto la Tabla 5 y la Figura 6.

Tabla 5. Horario de ocurrencia de delitos de narcotráfico y narcomenudeo. Período 2017-2019. (Excluye los decomisos de la Aduana en el complejo Puente Loyola).

\begin{tabular}{|c|c|c|}
\hline HORARIOS & NÚMERO DE DELITOS & '\% DE DELITOS \\
\hline MAÑANA (06 a 12 hs.) & 52 & $34,7 \%$ \\
\hline TARDE (12 a 20 hs.) & 32 & $21,3 \%$ \\
\hline NOCHE (20 a 06 hs.) & 60 & $40 \%$ \\
\hline SIN DATOS & 6 & $4 \%$ \\
\hline TOTAL & 150 & $100 \%$ \\
\hline
\end{tabular}

Fuente: Elaboración propia con datos de los portales digitales Clorinda al día, Crónicas de Clorinda, Central de Noticias Clorinda, Frontera y el portal oficial de la Policía de la Provincia de Formosa.

Figura 6. Horario de ocurrencia de los delitos de narcotráfico y narcomenudeo. Ciudad de clorinda. Período 2017-2019. (Excluye los decomisos de la Aduana en el complejo Puente Loyola)

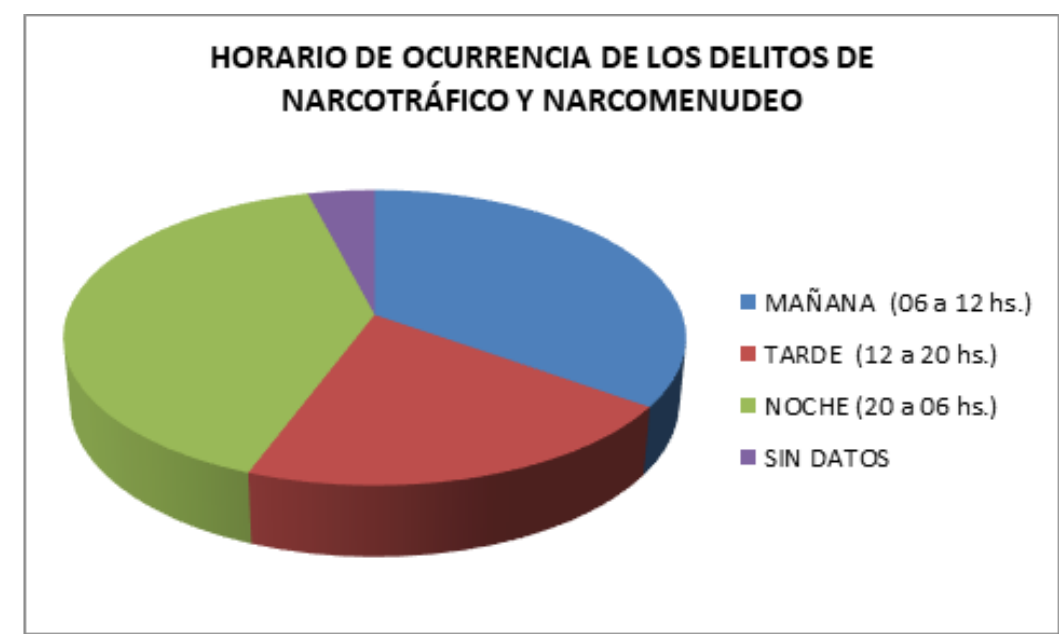

Fuente: elaboración propia con datos de los portales digitales Clorinda al día, Crónicas de Clorinda, Central de Noticias Clorinda, Frontera y el portal oficial de la Policía de la Provincia de Formosa.

\section{Conclusiones}

Como ya expresamos, el narcotráfico y el narcomenudeo constituyen los delitos sociales (contra la salud de las personas) más frecuentes en la ciudad de Clorinda.

Esto lo podemos afirmar analizando los delitos cometidos contra las personas, -unos 267 sobre 642de los cuales unos 150 fueron hechos relacionados con el narcotráfico y narcomenudeo, lo que constituye el 56,2\% de los mismos. Como dijimos anteriormente, esta cifra representa el 23,4\% del total de delitos de toda índole cometidos en la ciudad en el período estudiado.

Significa lo expuesto que el tráfico de estupefacientes tanto mayorista como al detalle se encuentra en tercer lugar en orden de ocurrencia de delitos en la cabecera departamental, sólo superado en número por los delitos de robos y de hurtos.

La comercialización de narcóticos es llevada a cabo en su gran mayoría por jóvenes adictos que buscan mediante esta actividad ilícita solventar sus propias adicciones, siendo los que llevan las ganancias los proveedores mayoristas de los dealers.

Afortunadamente no existen en la ciudad de Clorinda problemas que se desprendan de procesos de territorialización criminal como en otras localidades argentinas, ya que no se han identificado en la cabecera departamental bandas de narcotraficantes que disputen espacios de venta callejera. 
Las drogas comercializadas son la marihuana y la cocaína. No se desprende de la información periodística el consumo de paco o pasta base, lo que indica la ausencia de cocinas de cocaína. Tampoco se ha detectado en la ciudad de Clorinda la presencia de drogas sintéticas o de diseño.

Dentro de las modalidades de venta minorista de narcóticos se presentan en la ciudad de Clorinda la venta callejera barrial y la comercialización en domicilios particulares o quioscos domiciliarios.

El listado de barrios con mayor ocurrencia de delitos de narcotráfico y narcomenudeo es encabezado por el barrio 25 de Mayo, que acumula más del 14,7\% de los delitos de esa índole cometidos en la cabecera departamental.

Los barrios Centro, Libertad, $1^{\circ}$ de Mayo, Porteño Norte e Independencia lo siguen en número de hechos relacionados con la comercialización de drogas ilícitas. El resto de los barrios de la cabecera departamental presenta una relativamente baja ocurrencia de delitos vinculados al tráfico y a la venta minorista de narcóticos.

La tasa de delitos de narcotráfico y narcomenudeo de la ciudad de Clorinda se calculó en base a la población estimada por la Dirección Provincial de Estadísticas y Censos para los años 2017, 2018 y 2019, siendo la misma de 8,6 delitos cada 10.000 habitantes. Esta tasa referencia el promedio de las tasas resultantes de cada año analizado.

Desde el análisis de las jurisdicciones policiales, la Comisaría Subinspector Idelfonzo Vera acumula el mayor número de delitos relacionados a estupefacientes (60\%), siendo mucho menor y similar entre sí los porcentajes de delitos cometidos en las jurisdicciones restantes, las Sub-comisarías Territorios Nacionales, $(13,3 \%) 1^{\circ}$ de Mayo (14,7\%) y Destacamento El Porteño(10,7\%)

Interpretando la información obtenida podemos apreciar que en la ciudad de Clorinda existen puntos donde la media de delitos de narcotráfico y narcomenudeo es mayor que en el resto de los sectores urbanos. Estos puntos calientes o hot-spot se pueden identificar claramente, y en lo que respecta a lugares y modalidades podemos diferenciar la venta de narcóticos minorista que ocurre en mayor medida en el sector comprendido entre la pasarela de la Amistad y la terminal de ómnibus de Clorinda, (barrios Centro e Independencia) en pleno microcentro. En este sector predomina la venta callejera en el caso de la comercialización al detalle. También en este lugar se han decomisado algunos cargamentos de drogas al por mayor.

Asimismo, el barrio 25 de Mayo también es uno de los sectores con mayor ocurrencia y predominio de hechos de narcomenudeo, constituyéndose en sí mismo como una zona caliente. Aquí se han detectado muchos casos de comercialización de narcóticos en la modalidad de venta domiciliaria (bunkers o kioscos).

El Complejo Fronterizo San Ignacio de Loyola, -bajo jurisdicción de la Aduana Argentina- localizado sobre la ruta Nacional $\mathrm{N}^{\circ} 11$ entre los barrios Porteño Norte y Porteño Sur de la ciudad de Clorinda, constituye un punto caliente en lo que respecta al tráfico de estupefacientes a gran escala.

Por último, analizando los horarios de ocurrencia del delito relacionado al tráfico mayorista y minorista de drogas, podemos afirmar que no existe una franja horaria preferida para delinquir, siendo similar la cantidad de ilícitos cometidos durante la noche (60 delitos), y la mañana (52 hechos delictivos). La cantidad de delitos de esta índole baja durante horas de la tarde (32 hechos).

En definitiva, es preocupante el aumento de hechos delictivos relacionados al tráfico de narcóticos a gran y pequeña escala en la segunda ciudad en orden de importancia poblacional de la provincia de Formosa, sobre todo en lo que respecta al aumento del consumo de cocaína, fenómeno que comenzó a dilucidarse en los últimos años, ya que tradicionalmente el consumo de drogas entre los jóvenes fue esencialmente marihuana.

\section{Referencias bibliográficas}

Alvarado, Luis E. (2013) Microtráfico y narcomenudeo. Caracterización del problema de las drogas en pequeñas cantidades en Colombia. Documento de trabajo del Ministerio de Justicia y del Derecho Dirección de política contra las drogas y actividades relacionadas. Bogotá. Recuperado de https://www. odc.gov.co/Portals/1/Docs/oferta/FICHA-MICROTRAFICO NARCOMENUDEO_oct_2013.pdf

Cardozo, Osvaldo, Meretz, Iris. (2004) La Geografía del Crimen: utilidades y un estudio de caso en el Nordeste Argentino. En Actas del XXIV Encuentro de Geohistoria Regional. Instituto de Investigaciones Geohistóricas (IIGHI) - CONICET, Resistencia, p. 109-113. 
Conte, Ricardo Omar, Merlo, Orlando Daniel. (2018) El narcomenudeo como expresión del delito urbano en la ciudad de Formosa. En IGA, Revista del Instituto de Geografía Aplicada de la Facultad de Filosofía, Humanidades y Artes de la Universidad Nacional de San Juan. Edición digital. San Juan, 21-32. ISSN 15141942. Recuperado de https://www.revistaiga.unsj.edu.ar

Diario Central de noticias Clorinda. Recuperado de https://centralnoticiasclorinda.com.ar

Diario Clorinda al día. Recuperado de https://www.clorindaaldia.com/

Diario Crónicas de Clorinda. Recuperado de http://cronicasdeclorinda.blogspot.com/

Diario Frontera. Recuperado de https://diariofrontera.com.ar/noticias/

Eck, John. (2005) Crime Hot Spots: What They Are, Why We Have Them, and How to Map Them. En Mapping Crime: Understanding Hot spots. NIJ Special Report. U.S. Department of Justice. Office of Justice Programs. National Institute of Justice. Washington DC. Recuperado de https:/www.discovery.ucl. ac.uk/11291/1/11291.pdf

Gañan, Javier. (2017) Entre la negación y la adaptación. La política pública del Ministerio de Seguridad de la Provincia de Santa Fe en relación al narcomenudeo a partir del caso Los Monos. Rosario, 2012- 2015. Tesina de Licenciatura. Facultad de Ciencia Política y Relaciones Internacionales. Universidad Nacional de Rosario. 103 Páginas. Recuperado de https://rephip.unr.edu.ar/xmlui/bitstream/handle/2133/9734/Tesina\%20 de\%20grado\%20Ciencia\%20Pol\%c3\%adtica\%20Javier\%20Ga\%c3\%b1\%c3\%a1n.pdf?sequence=3\&isAllowed=y

Guzmán, Carlos Enrique. (1998) Clorinda. Un enfoque geográfico de su urbanización. Tesina de Licenciatura. Carrera de Licenciatura en Geografía. Facultad de Humanidades. Universidad Nacional de Formosa. Inédito.

Kessler, Gabriel. (2009) El sentimiento de inseguridad. Sociología del temor al delito. Buenos

Klipphan, Andrés. (2018) 31 de marzo. Las alarmantes cifras que mueve el narcotráfico en Argentina para el consumo interno. Infobae). Disponible en: https://www.infobae.com/sociedad/2018/03/31/lasalarmantes-cifras-que-mueve-el-narcotrafico-en-argentina-para-el-consumo-interno/

Lahosa, Joseph. (2002) Delincuencia y ciudad. Hacia una reflexión geográfica comprometida. En Biblio 3W. Revista Bibliográfica de Geografí y Ciencias Sociales, 7(349). Universidad de Barcelona. Barcelona. Recuperado de http//www.ub.edu/geocrit/b3w-349.htm.

Pelacchi, Adrián Juan. (2000) Tratado sobre la Seguridad Pública. Buenos Aires. Editorial Policial. ISBN 950907151X, 9789509071513.

Pontón, Daniel. (2013) La economía del narcotráfico y su dinámica en América Latina. Íconos. Revista de Ciencias Sociales. Facultad Latinoamericana de Ciencias Sociales- Sede Académica de Ecuador. (47). ISSN: 1390-1249. Quito. Recuperado de http://www.redalyc.org/articulo.oa?id=50928911009

Portal de la Policía de la provincia de Formosa. Recuperado de https://www.formosa.gob.ar/policia

Sangiorgio, Belisario. (2018) 28 de octubre. Betharram. Otro enclave para los clanes y las drogas. La Nación. Recuperado de https://www.lanacion.com.ar/2186122-betharram-otro-enclave-clanes-drogas

Sangiorgio, Belisario. (2019) 21 de febrero. Aumentó 145\% en tres años la cantidad de detenidos por causas de drogas. La Nación. Recuperado de https://www.lanacion.com.ar/seguridad/narcotrafico-2015aumento-147-cantidad-detenidos-nid2221657

Souto Zavaleta, Mariana, Delfino, Paula, Sarti, Silvio Sebastián. (2019) Consideraciones críticas sobre el abordaje del problema del narcotráfico en Argentina. En IUS. Revista del Instituto de Ciencias Jurídicas de Puebla, 13(44). México. E-ISSN:1870-2147. Recuperado de https://www.redalyc.org/ jatsRepo/2932/293261227004/index.html

Van Soomeren, Paul. (2007) El Delito y la Inseguridad Subjetiva desde la Arquitectura y el Urbanismo. Amsterdam. Revista DSP-Groep. 241-287. Recuperado de http://www.veilig-ontwerp-beheer. nl/publicaties/el-delito-y-la-inseguridad-subjetiva-desde-la-arquitectura-y-el-urbanismo

Vilalta Perdomo, Carlos J. (2009) La geografía local del narcomenudeo: patrones, procesos y recomendaciones de política urbana. Revista Estudios Demográficos y Urbanos, 24(1). ISSN:0186-7210. Pp. 49-77 El Colegio de México, A.C. Distrito Federal, México. Recuperado de http://e-spacio.uned.es/fez/ collection/bibliuned:revistaDerechoPenalyCriminologia-2013-9

Zamudio Angles, Carlos Alberto. (2008) ¿Qué es el narcomenudeo? Un acercamiento etnológico. Revista Liberaddictus, (103). ISSN:1405-6569. Recuperado de https://dialnet.unirioja.es/servlet/ articulo? codigo $=2704534$ 